\title{
Dinamika Anti Syiah di Kota Manado
}

\author{
Taufani Taufani ${ }^{1}$, Ismail Suardi Wekke ${ }^{2}$ \\ ${ }^{1}$ Fakultas Ushuluddin, Adab, dan Dakwah IAIN Manado, North Sulawesi, Indonesia \\ ${ }^{2}$ STAIN Sorong, West Papua, Indonesia \\ taufani@iain-manado.ac.id \\ Presented in \\ International Symposium on Frontiers of Southeast Asia Studies (ISoFSEAS) 2017 \\ October 9 - 11, 2017, Kuala Terengganu, Malaysia
}

\begin{abstract}
Sentimen Anti Syiah belakangan ini tumbuh menguat di Indonesia. Sentimen itu tidak hanya terjadi di daerah yang mayoritas Islam, tetapi juga terjadi di daerah minoritas Islam seperti di Kota Manado. Studi ini ingin mengurai lebih jauh tentang dinamika anti Syiah di Kota Manado dan faktor-faktor yang memicu munculnya sentimen tersebut. Penelitian ini adalah penelitian kualitatif di mana data-datanya diperoleh melalui observasi, wawancara mendalam, studi dokumentasi, dan kajian kepustakaan. Studi ini menunjukkan bahwa sentimen anti Syiah mulai tumbuh pada tahun 2008-2009 dan mencapai puncaknya pada tahun 2012. Di tahun 2016, sentimen anti Syiah menguat kembali ditandai dengan hadirnya berbagai spanduk bernada kebencian yang berbunyi "Syiah Bukan Islam” yang terpasang di berbagai sudut kota. Menariknya, spanduk-spanduk tersebut berkonten sama dengan spanduk-spanduk yang yang bertebaran di berbagai kota di Indonesia. Sentimen anti Syiah di Manado terjadi karena adanya persaingan perebutan lahan ekonomi dan juga perebutan kuasa dan pengaruh di antara para mubaligh. Internet dan media sosial juga memainkan peranan penting dalam mengeskalasi kebencian karena ia memberikan informasi yang bias dan tidak objektif mengenai Syiah.
\end{abstract}

\section{Latar Belakang Masalah}

Konflik keagamaan di Indonesia tumbuh cukup subur di era pasca Orde Baru. Konflik keagamaan di Indonesia mengambil bentuk aksi damai dan aksi kekerasan. Konflik keagamaan di Indonesia muncul disebabkan oleh berbagai isu, yakni isu moral, sektarian, komunal, terorisme, politik-keagamaan, dan isu lainnya (Ali-Fauzi, dkk, 2009: 9).

Sejumlah laporan tahunan kebebasan beragama dan berkeyakinan yang dirilis oleh sejumlah lembaga yang konsen pada isu ini baik Komnas HAM, The Wahid Institute, maupun Setara Institute melaporkan bahwa konflik keagamaan di Indonesia beberapa tahun terakhir ini ditandai dengan dua hal dominan, yakni pelarangan pembangunan rumah ibadah bagi kalangan minoritas di berbagai daerah dan juga kekerasan terhadap penganut aliran yang dicap sesat, seperti Syiah dan Ahmadiyah (Laporan Komnas HAM, 2016; Laporan Wahid Institute, 2015; Laporan Setara Institute, 2016)

Pelarangan pembangunan rumah ibadah di sejumlah daerah menjadi hal yang mengemuka belakangan ini dalam isu kebebasan beragama dan berkeyakinan. Padahal, rumah ibadah adalah ekpresi beragama yang menjadi sarana untuk beribadah (Wekke, 2013a). Di berbagai daerah, para kelompok minoritas mengaku dipersulit dalam proses pendirian rumah ibadah. Jawa Barat menjadi daerah dengan tingkat intoleransi tertinggi (Laporan Komnas HAM, 2016; Laporan Wahid Institute, 2015; Laporan Setara Institute, 2016). Pelarangan pembangunan gereja dan kekerasan terhadap penganut Syiah dan Ahmadiyah terpantau cukup tinggi di propinsi ini.

Kota-kota di Timur Indonesia selalu menunjukkan keharmonian (Wekke, 2013b). Bahkan menunjukkan perjumpaan antara adat dan agama (Wekke, 2017). Dalam berbagai survei dan laporan 
terdahulu, Sulawesi Utara khususnya kota Manado selalu menempati posisi teratas sebagai daerah yang paling toleran. Sebenarnya prestasi yang ditorehkan oleh Kota Manado sebagai kota yang toleran bukan baru terjadi belakangan ini. Sejak dulu, Kota Manado telah dikenal sebagai role model kota kerukunan di Indonesia. Citra Manado sebagai kota toleran muncul setelah ia mampu melalui efek yang ditimbulkan dari daerah konflik yang berbatasan langsung dengannnya di awal tahun 2000-an. Seperti diketahui bahwa secara geografis, Manado diapit langsung oleh segitiga konflik, yakni Poso di sebelah Selatan, Ketapang, Sambas, dan Sampit di sebelah Barat, dan Maluku dan Maluku Utara di sebelah Timur (Mantu, 2015: 40-41). Hal ini menunjukkan bahwa Manado memiliki tingkat kerentanan yang cukup tinggi pada konflik karena kondisi geografisnya berbatasan langsung dengan beberapa daerah konflik.

Namun yang terjadi adalah sebaliknya. Manado menjadi tempat pelarian bagi para korban konflik Poso dan Ambon (Mantu, 2015: 40-41). Awalnya masyarakat Manado khususnya yang beragama Kristen sempat sedikit dihantui oleh kekhawatiran akan munculnya konflik baru di "kota seribu gereja" ini karena kebanyakan dari pengungsi tersebut adalah beragama Islam. Mereka khawatir umat Muslim yang datang dari daerah bertikai tersebut masih menyimpan dendam kepada para penganut Kristiani. Namun, apa yang dikhawatirkan cenderung tidak terjadi. Masyarakat Manado dan para pengungsi ternyata dapat saling menerima dan saling membaur satu sama lain. Sampai sekarang beberapa dari pengungsi tersebut telah tinggal menetap dan juga telah mencapai kesuksesan di Kota Manado.

Ketika konflik sedang memanas di Ambon dan Poso, situasi di Manado cenderung berjalan aman dan kondusif. Berbagai sudut kota dipenuhi dengan narasi perdamaian "torang samua basudara" (kita semua bersaudara) untuk menunjukkan bahwa Kota Manado adalah rumah yang aman dan nyaman bagi siapa saja termasuk bagi para pengungsi.

Namun beberapa tahun belakangan ini, Manado telah mengalami penurunan dalam hal toleransi beragama. Laporan Tahunan Kebebasan Beragama dan Berkeyakinan yang dirilis oleh Komnas HAM di tahun 2016 melaporkan bahwa Manado menjadi salah satu kota di Indonesia yang memiliki permasalahan terkait pembatasan pembangunan rumah ibadah, yakni pembangunan Masjid Jabal Nur Manado dan juga penolakan Masjid di Eks Kampung Texas Manado (Laporan Komnas HAM, 2016). Menurunnya tingkat toleransi beragama di Kota Manado tidak hanya berkisar pada persoalan sulitnya akses pembangunan rumah ibadah bagi kalangan minoritas, tetapi juga pada menguatnya narasi kebencian di ruang publik khususnya yang terkait dengan isu sektarian. Isu sektarian dalam hal ini mengacu pada perseteruan terkait interpretasi ajaran dan juga status kepemimpinan dalam suatu komunitas keagamaan (konflik intra umat beragama) (Ali-Fauzi, dkk, 2009: 9). Kekerasan dan protes terhadap eksistensi kelompok Syiah dan Ahmadiyah adalah contoh yang relevan dalam kategori isu sektarian.

Beberapa tahun belakangan ini, Kota Manado dilanda dengan isu yang berbau sektarian. Hal ini ditandai dengan munculnya berbagai spanduk yang bernada kebencian dan permusuhan, seperti "Syiah Bukan Islam". Tidak hanya itu, mimbar-mimbar keagamaan juga dipenuhi dengan wacana anti Syiah. Hal ini secara tidak langsung menunjukkan bahwa telah terjadi pergeseran sikap dan pemahaman keagamaan di tengah masyarakat Manado.

Studi ini akan berfokus pada dinamika anti Syiah di Kota Manado. Studi ini menarik karena memotret tentang fenomena anti Syiah di tengah umat Islam (Sunni) yang merupakan minoritas di Kota Manado dimana pendidikan justru menjadi wadah perjumpaan umat beragama (Wekke, 2013c). Selama ini sentimen anti Syiah yang berujung pada kekerasan fisik maupun verbal lebih banyak dipotret di daerah yang berpenduduk mayoritas Islam (Sunni), tetapi studi ini mengangkat tentang sentimen kebencian terhadap Syiah di daerah yang berpenduduk mayoritas Kristen. Studi ini akan fokus pada dinamika Anti Syiah di Kota Manado dan faktor yang memicu munculnya sentimen anti Syiah.

\section{Metode Penelitian}


Penelitian ini adalah penelitian kualitatif di mana data yang diperoleh berasal dari observasi, wawancara mendalam, studi dokumentasi, dan kajian kepustakaan. Informan dalam penelitian dipilih melalui snowball sampling. Penelitian ini mengambil tempat di Kota Manado dan mewawancarai tujuh orang informan yang dianggap berpengaruh dan memiliki pengetahuan yang cukup baik tentang Syiah, agar dapat memberikan data yang lengkap dan komprehensif. Mereka itu adalah tokoh yang dianggap sesepuh pada komunitas Syiah, tokoh muda Syiah, kalangan pengurus dalam organisasi Syiah dan beberapa tokoh penting lainnya yang menjadi rekomendasi dari para informan.

\section{Diskusi}

Manado adalah sebuah kota yang memiliki keragaman yang unik. Walaupun banyak didiami oleh mayoritas penganut Kristiani, tetapi orang tak akan sulit menemukan tempat yang menjadi kantong-kantong umat Islam, diantaranya Kampung Arab, Kampung Ternate, Kampung Bugis, Kampung Jawa, Banjer, Perkamil, Mahawu, Maasing, Tuminting, dsb. Walaupun dikenal sebagai daerah yang berpenduduk mayoritas Kristen alias "negeri seribu gereja", namun secara historis Kota Manado atau tanah Minahasa telah lama bersentuhan dengan Islam tepatnya di abad ke 19 (Kembuan, 2016). Imam Bonjol dan Kiai Modjo adalah sedikit contoh dari beberapa tokoh Islam yang pernah menghabiskan hidupnya berdakwah di kota ini.

Manado selama ini telah dikenal sebagai kota percontohan kerukunan (city of tolerance) di Indonesia karena perbedaan dan keragaman yang menjadi ciri khas kota ini dapat terkelola dengan baik. Hanya saja belakangan ini, telah terjadi sedikit ketegangan yang berpotensi mengancam iklim kerukunan antar dan intra umat beragama. Peristiwa demonstrasi pelarangan pembangunan Masjid Kampung Texas di Manado pada tahun 2016 sedikit banyaknya telah memicu ketegangan hubungan antara pemeluk Islam dan Kristen. Tak hanya itu saja, sentimen kebencian intra umat beragama seperti Islam juga mengalami peningkatan belakangan ini.

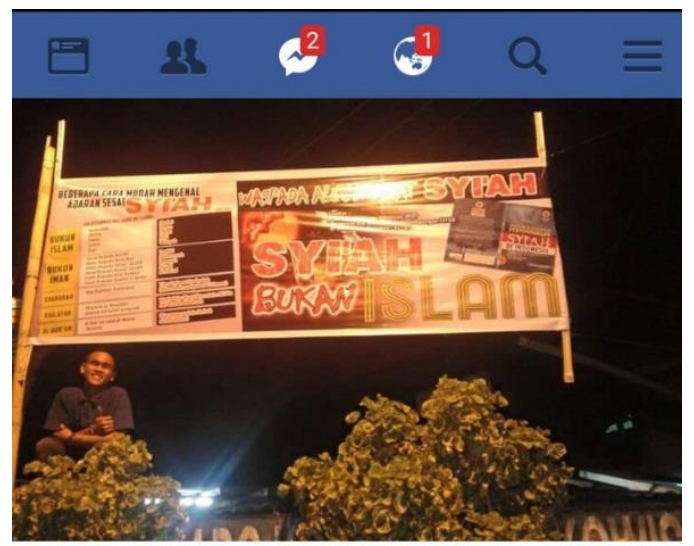

Kiki Rizky Kiki

Wah kota manado ternya ada juga yg tegas dalam masalah aqidah, \#komodalam

"Foto Kiki Rizky Kiki" dalam Unggah Seluler · 12 Juni $2016 \cdot(2)$

Tampilkan Ukuran Penuh · Pilihan Lainnya

Pada tahun 2016, kita akan mudah menemukan berbagai spanduk yang mengandung unsur kebencian dan permusuhan terhadap Syiah di berbagai sudut tempat, seperti di Jarod, Kampung Arab, dan Komo Dalam yang merupakan kantong-kantong Islam. Di spanduk itu tertulis bahwa "Syiah bukan Islam". Dalam spanduk itu tertulis bahwa Rukun Islam dan Rukun Iman Syiah berbeda dengan apa yang diyakini oleh kaum mayoritas Islam.

Masa awal munculnya sentimen Anti Syiah di Manado terjadi pada tahun 2008, ketika beberapa masjid di Manado diisi dengan berbagai ceramah anti Syiah, salah satunya di Masjid Komo Dalam. Dikisahkan bahwa pada waktu itu, seorang mubaligh anti Syiah membawa khutbah yang cenderung bias terhadap kisah terbunuhnya cucu Nabi yakni Husein di Padang Karbala. Untuk tidak mengatakan, bahwa sang khatib tersebut tidak menyetujui sepenuhnya kebenaran kisah tragis terbunuhnya Husein di Padang Karbala yang selama ini sering diekspose oleh kalangan Syiah.

Kala itu banyak jamaah yang menjadi resah dengan adanya ceramah tersebut karena dianggap sangat tendensius. Karena itulah, jamaah masjid Komo Dalam kemudian berinisiatif untuk mengundang Muzwir Luntajo, dosen IAIN Manado dan juga warga asli Komo Dalam yang sekarang berdomisili di daerah Malendeng, untuk mengisi khutbah di Jumat berikutnya, karena ia dianggap 
mumpuni untuk menjelaskan persoalan ini secara objektif dengan kapasitasnya sebagai alumni Pesantren Al-Khairat Palu dan juga sebagai dosen kampus Islam IAIN Manado.

Kala itu Muzwir berusaha untuk menjelaskan seobjektif mungkin bahwa terbunuhnya Husein di Padang Karbala secara tragis - sebagaimana yang sering digambarkan oleh para penganut Syiahadalah benar adanya berdasarkan kajian historis. Dalam posisinya sebagai akademisi, Muzwir secara implisit ingin menyampaikan pesan pada jamaah bahwa umat Islam harus tetap adil dan objektif dalam melihat dan mengkaji suatu masalah dan hendaknya tidak mengedepankan sikap fanatisme yang berlebihan dalam bermazhab.

Sejak kejadian itu, tuduhan sebagai Syiah pada Muzwir menjadi tak terelakkan di berbagai mimbar masjid. Tuduhan tersebut dilakukan oleh Ustad Abdurrahman Mahrus dan para pengikutnya. Tidak terima dengan fitnah dan tuduhan itu, maka Muzwir melaporkan Mahrus beserta para pengikutnya di kepolisian atas tuduhan pencemaran nama baik. ${ }^{1}$ Ada indikasi bahwa tuduhan terhadap Syiah yang dialamatkan pada Muzwir tak bisa dilepaskan dari adanya keinginan kelompok Abdurrahman Mahrus (yang umumnya pendatang baru di Komo Dalam) untuk menguasai kepengurusan Badan Takmir Masjid Komo Dalam yang selama ini dikuasai oleh penduduk asli setempat dan juga keluarga besar Muzwir Luntajo. Karena itu, mereka melakukan berbagai strategi, salah satunya dengan melakukan pembunuhan karakter terhadap Muzwir.

Sebagai dampak dituduhnya Muzwir sebagai penganut Syiah, di tahun 2009-2011 muncul berbagai hasutan di berbagai mimbar masjid agar para jamaah tidak memasukkan anak-anaknya ke IAIN Manado karena dianggap sebagai sarang Syiah. Sekitar tahun 2009, salah satu mubaligh anti Syiah, Arya Amir pernah melakukan ceramah yang menyerang dan menjelek-jelekkan dosen IAIN Manado di daerah Wonasa, namun kegiatan itu dibubarkan oleh mahasiswa IAIN Manado karena merasa gerah dengan ceramah Arya Amir yang selalu menuduh dan memfitnah dosen mereka sebagai penganut Syiah. ${ }^{2}$

Dalam konteks Kota Manado, ada beberapa tokoh mubaligh yang getol menyuarakan sentimen anti Syiah, yakni Abdul Rahman Mahruz, Yasir Bahmid, dan Arya Amir. Dalam berbagai ceramahnya, mereka kerap mempropagandakan kebencian dan permusuhan terhadap Syiah. Mereka juga kerap mengkafirkan dan menyatakan darah orang Syiah halal untuk dibunuh.

Hal yang sering diangkat dalam ceramah mereka untuk menyudutkan Syiah adalah persoalan klasik, yakni tuduhan bahwa Syiah mengkafirkan dan mencaci maki Sahabat (Abu Bakar, Umar, dan Utsman) dan Istri Nabi (Aisyah), salatnya orang Syiah hanya tiga waktu bukan lima waktu, Syiah memiliki Al-Quran yang berbeda, Syiah menghalalkan praktik nikah mut'ah, Syiah menuhankan Ali, Syiah memiliki Rukun Islam dan Iman yang berbeda dengan mayoritas Islam, Syiah memiliki syahadat yang berbeda, doktrin taqiyah dianggap sebagai doktrin kemunafikan, dan masih banyak lagi. Karena seringnya mereka mengutuk dan mencaci maki Syiah, akhirnya umat Islam di Manado mengenal Syiah secara luas, padahal dulunya hanya segelintir umat yang mengetahui hal itu.

Sentimen anti Syiah mulai menjadi bahan santapan ceramah di berbagai mimbar keagamaan di Manado pada tahun 2009 tatkala seorang mubaligh asal Sulawesi Utara yang telah bermukim lama di Kalimantan Timur (Kaltim), yakni Habib Muhsin Bilfagih, kembali menetap di Manado pada tahun 2006. Kedatangan Habib Muhsin turut memicu menguatnya sentimen Anti Syiah. Habib Muhsin menjadi sasaran tembak di berbagai mimbar keagamaan oleh para tokoh anti Syiah dengan tuduhan sebagai seorang penganut Syiah dan karenanya harus diwaspadai. Dalam sebuah wawancara Habib Muhsin menyatakan bahwa:

\footnotetext{
${ }^{1}$ Berdasarkan wawancara dengan Muzwir Luntajo pada tanggal 7 Maret 2017 di IAIN Manado. Muzwir akhirnya menarik laporannya di kepolisian di tahun 2009 setelah ia diberi nasehat oleh pimpinan Al-Khairat pasca menghadiri haul Al-Khairat tahun 2009 di Palu.

${ }^{2}$ Berdasarkan wawancara dengan Muzwir Luntajo pada tanggal 7 Maret 2017 di IAIN Manado.
} 
"Saya juga bingung kenapa di Manado saya di tolak, padahal di Kalimantan, tepatnya di Samarinda, Balikpapan, dan Tarakan, saya tak ada masalah dengan orang-orang disana, bahkan hubungan saya sangat baik dan mesra dengan mereka sampai sekarang. "”

Saya melihat bahwa sentimen anti Syiah yang dialamatkan oleh para mubaligh pembenci Syiah kepada Habib Muhsin sebenarnya sarat dengan muatan ekonomi-politik dan juga perebutan pengaruh dan kuasa. Kehadiran Habib Muhsin di Manado telah mencuri panggung dan mengancam popularitas para mubaligh anti Syiah. Bagaimana tidak, sebagai seorang pendatang baru di Kota Manado, Habib Muhsin dengan cepat mampu merebut hati sebagian umat Islam, pejabat daerah, dan tokoh-tokoh lintas iman, sehingga menimbulkan kecemburuan di sebagian kalangan mubaligh.

Adanya tuduhan sebagai penganut Syiah yang dialamatkan kepada Habib Muhsin (Habib Muhsin dalam setiap kesempatan selalu membantah dan mengklarifikasi bahwa dirinya bukan seorang Syiah dan tuduhan yang dialamatkan kepada dirinya adalah fitnah) tak bisa dilepaskan oleh beredarnya rekaman lantunan munajat kepada Ahlul Bait (keluarga Nabi) yang dibawakan oleh putranya yang bernama Fauzan Bilfagih di kalangan umat Islam di Manado. Bagi kelompok anti Syiah, hal ini dianggap sebagai praktik Syiah. Padahal di kalangan NU, hal ini merupakan sebuah bentuk amaliyah. Di samping itu, banyak umat Islam di Manado mengetahui bahwa saudara Habib Muhsin yang menetap di Kaltim adalah penganut Syiah. Beberapa umat Islam Manado mengetahui hal ini karena para jamaah haji asal Manado kerap bersilaturahmi dengan saudara Habib Muhsin ketika transit di Kaltim sesaat sebelum bertolak haji. Hal-hal inilah yang menjadi jalan masuk bagi para kelompok anti Syiah di Manado untuk menuduh Habib Habib Muhsin sebagai seorang penganut Syiah. $^{4}$

Popularitas Habib Muhsin sebagai mubaligh pendatang baru di Manado menjadi semakin menanjak karena dalam waktu yang relatif singkat, Habib Muhsin dapat menggaet jamaah dalam jumlah yang relatif besar di bawah Majelis Al Hikam yang dipimpinnya. Majelis Al-Hikam dikenal memiliki banyak jamaah baik di Manado maupun di berbagai wilayah sekitar Manado seperti Tanawangko, Kema, Belang, Tumbak, Bitung, dan sebagainya. Karena itu, untuk menjatuhkan citra dan nama baik Habib Muhsin, maka para mubaligh yang terancam dengan kehadirannya membuat stigma bahwa Habib Muhsin adalah seorang penganut Syiah dan juga seorang habib palsu.

Sentimen anti Syiah menjadi semakin membesar dan menguat tatkala Agil Basarewang menyatakan diri masuk Syiah sekitar tahun 2009. Agil dianggap sebagai ancaman karena ia dikenal sebagai figur yang mumpuni dalam ilmu agama khusunya dalam penguasaan teks klasik karena ia merupakan alumni Pesantren Gontor dan juga memiliki kekuatan ekonomi yang kuat dan mapan sebagai seorang pengusaha besi tua dan importir beras dari Thailand. Sebelum menyatakan diri pindah ke aliran Syiah, Agil sebenarnya telah belajar tentang Syiah dari berbagai literatur.

Bergabungnya Agil menjadi penganut Syiah telah menimbulkan kontroversi di Kota Manado khususnya di Kampung Arab yang merupakan basis Abdurrahman Mahrus. Di masa awal ia bergabung menjadi penganut Syiah, Agil menunjukkan identitas ke-Syiah-annya dengan mengenakan pakaian hitam khas Syiah sembari menyampaikan khutbah Jumat tentang syahidnya Husein, cucu Nabi Muhammad SAW di Padang Karbala. Yang menarik dalam khutbahnya adalah Agil tidak menyematkan gelar Radiyallahu Anhu (RA) di belakang nama Husein sebagaimana yang telah menjadi kebiasaan dalam tradisi Sunni, melainkan ia menyematkan gelar Alaihissalam (AS) pada nama belakang Husein yang merupakan kebiasaan dalam tradisi Syiah untuk menghormati para Ahlul Bait.

\footnotetext{
${ }^{3}$ Berdasarkan wawancara dengan Habib Habib Muhsin Bilfagih tanggal 4 Maret 2017 di kediaman beliau di Perkamil.

${ }^{4}$ Berdasarkan wawancara dengan Habib Habib Muhsin Bilfagih tanggal 4 Maret 2017 di kediaman beliau di Perkamil.
} 
Ketika melakukan ritual salat jumat, Agil memilih untuk meluruskan tangannya (irsal) sebagaimana yang menjadi tradisi dalam fikih Ja'fari yang diyakini oleh penganut Syiah. Setelah kejadian itu, Agil digempur bertubi-tubi dengan berbagai ujaran kebencian karena identitasnya sebagai Syiah. Walaupun sering digempur dengan berbagai ujaran kebencian Syiah, namun Agil tak ambil peduli karena sebelum berkonversi menjadi Syiah, ia telah mempertimbangkan dengan matang dampak yang akan ditimbulkan dari keputusannya itu. Walaupun sering diserang dengan berbagai fitnah akibat keputusannya menjadi penganut Syiah, namun Agil tetap berani dan frontal menantang mereka yang kerap menyerang dirinya. Dalam beberapa kesempatan, ia kerap mengajak diskusi bahkan melakukan debat terbuka dengan mereka yang anti Syiah, termasuk Abdurrahman Mahrus dan Arya Amir, namun ajakan Agil selalu ditolak.

Kebencian terhadap Syiah pasca bergabungnya Agil menjadi penganut Syiah, menjadi sangat gencar dilakukan. Sentimen kebencian itu dilakukan di mimbar masjid, majelis taklim, acara takziyah, dan juga melalui selebaran.

Pada tahun 2010, Abdurrahman Mahrus menginisiasi kegiatan dialog Sunni-Syiah dengan menghadirkan K.H. M. Baharun di Masjid Istiqlal Kampung Arab. Sekilas kegiatan ini terkesan ingin menjembatani hubungan antara Sunni-Syiah, tetapi yang terjadi kemudian adalah sebaliknya. Dialog ini tidak mengundang dan menghadirkan tokoh Syiah, sehingga dialog hanya berlangsung satu arah. Baharun selaku pemateri pada waktu itu menghantam dan menguliti Syiah secara habis-habisan dengan menggunakan isu-isu lama yang selama ini selalu terdengar di berbagai mimbar keagamaan. Melihat ini, Kindi Bilfagih selaku salah satu peserta yang hadir dalam dialog itu mengajukan pertanyaan sekaligus keberatan kepada pemateri dan pelaksana acara karena tidak melibatkan penganut Syiah, sehingga dialog cenderung berjalan satu arah dan tidak seimbang. ${ }^{5}$

Di tahun yang sama, di Kota Manado tersebar sejumlah selebaran anti Syiah di mana di dalamnya dicantumkan nama-nama tokoh yang dianggap sebagai penganut Syiah di Manado, di antaranya adalah Habib Arifin Assagaf, Agil Basarewang, Habib Habib Muhsin Bilfagih, dan masih banyak lagi. ${ }^{6}$ Setelah itu, sentimen anti Syiah semakin menjadi-jadi di mimbar masjid. Dalam beberapa ceramah, jamaah kerap diingatkan untuk mewaspadai tokoh-tokoh yang dianggap sebagai penganut Syiah, seperti Habib Arifin Assagaf, Habib Habib Muhsin Bilfagih, Agil Basarewang, Habib Husen Assagaf, Habib Hasan Molachele, Waston Cong Biahimo, Mahmud Lihawa, Awin Chalid, Taher Mongai, Handri Deu, Rusydin Ali, Bram Bason, Syarif Lakasan, Raflin Yusuf, Muhammad Nur Bongkang, dan Muzwir Luntajo.?

Pada tahun 2013, Yaser Bahmid yang juga merupakan mubaligh anti Syiah menginisiasi kegiatan diskusi tentang Syiah di Masjid Raya Ahmad Yani dan Kantor NU Sulut dengan mengundang K.H. Idrus Romli, tokoh NU Garis Lurus. NU Garis Lurus selama ini kerap mengklaim diri sebagai salah satu bagian dari NU yang memiliki tugas untuk menyelamatkan NU dari pahampaham yang sesat dan menyesatkan. Kegiatan diskusi tentang Syiah ini mengundang berbagai elemen umat Islam termasuk penganut Syiah itu sendiri. Dalam diskusi ini, Idrus Romli menyerang Syiah dengan berbagai tuduhan klasik yang selama ini selalu dialamatkan pada Syiah. ${ }^{8}$

Dibandingkan dengan Mahrus, metode dan pendekatan yang dilakukan Yaser dalam menyerang Syiah cenderung tidak sefrontal Mahrus. Dulunya Yaser juga dikenal sangat frontal dalam

${ }^{5}$ Berdasarkan wawancara dengan Kindi Bilfagih tanggal 4 Maret 2017 di kediaman beliau di Perkamil.

${ }^{6}$ Berdasarkan wawancara dengan Kindi Bilfagih tanggal 4 Maret 2017 di kediaman beliau di Perkamil. Pasca beredarnya selebaran tesebut, Kindi Bilfagih mengunjungi rumah Abdurrahman guna mengklarifikasi isi selebaran tersebut. Sayangnya, Abdurrahman Mahrus tidak berada di rumah waktu itu.

${ }^{7}$ Berdasarkan wawancara dengan Habib Hasan Molachele tanggal 3 Maret 2017 di kediaman beliau di Kampung Arab.

${ }^{8}$ Berdasarkan wawancara dengan Asri Rasjid, Ketua ABI Sulut pada tanggal 8 Maret 2017 di Warkop Lentera Bersehati. 
menyerang Syiah di setiap ceramahnya. Namun belakangan, Yaser cenderung berhati-hati memainkan isu anti Syiah. Menurut penulis, lunaknya metode dan pendekatan Yaser dalam menyerang Syiah dipengaruhi oleh jabatan strategis yang sedang ia emban, yakni sebagai Rois Syuriah NU Manado. Hal ini menuntut Yaser untuk bersikap moderat sehingga sejalan dengan ideologi dan garis organisasi NU yang menekankan pada toleransi dan moderatisme. Selain itu, kedekatan Yaser dengan pemerintah daerah yang ditunjukkan dengan seringnya Yaser diundang dalam berbagai kegiatan pemerintah khususnya yang berkaitan dengan isu kebhinekaan telah "memaksa" Yaser untuk mengubah strategi dakwahnya dari frontal menjadi lebih lunak.

Pada tahun 2016, warga Manado kerap menemukan berbagai spanduk propaganda anti Syiah yang bertuliskan "Syiah bukan Islam" yang dipasang di berbagai tempat seperti di Jarod, Kampung Arab, dan Komo Dalam. Dalam spanduk itu dikatakan bahwa Rukun Islam dan Rukun Iman kaum Syiah itu berbeda dengan apa yang diyakini oleh kaum Sunni. Menurut laporan Setara Institute (2016) spanduk anti Syiah telah muncul sebelumnya di tahun 2013 tepatnya di Yogyakarta. Kejadian ini menjadi terulang kembali di tahun 2015 dan penyebarannya cenderung menjadi lebih masif di berbagai daerah di Indonesia.

Ada indikasi bahwa adanya spanduk "Syiah Bukan Islam" yang tersebar di beberapa sudut tempat di Kota Manado adalah aksi yang dilakukan secara terstruktur, sistematis, dan masif secara nasional dan disponsori oleh sebuah kelompok aliansi tertentu. Indikasi ini muncul karena rentang waktu pemasangan spanduk-spanduk tersebut berlangsung secara bersamaan dan dilakukan secara masif di berbagai daerah di Indonesia. Yang menarik adalah pesan yang disampaikan dalam spandukspanduk itu cenderung seragam.

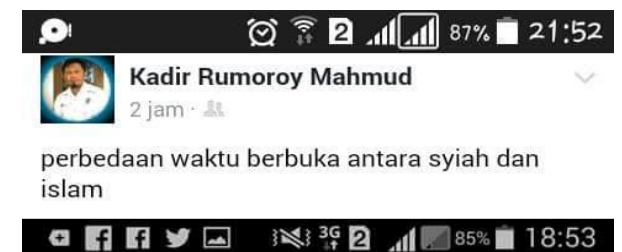

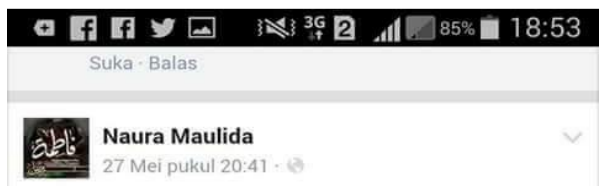

\section{Dulu sblm mengenal} Madzhab Ahlulbait ini, jika trdengar Suara adzan Ingsng brbuka puasa, pdhl msh terang blm gelap...8
Sentimen anti Syiah di Manado juga tak dapat dilepaskan dari kehadiran media sosial semacam Facebook. Banyak orang yang dulunya tak kenal dengan Syiah akhirnya menjadi tahu. Para pembenci Syiah di media sosial kerap mengeluarkan pesan kebencian dan permusuhan bahwa Syiah bukanlah Islam.

Internet juga memainkan peranan penting terhadap meningkatnya kebencian terhadap Syiah karena berbagai konflik yang terjadi di Timur Tengah sering mengkambinghitamkan Syiah sebagai dalang di baliknya. Belum lagi, segala informasi yang tersaji di internet mengenai Syiah cenderung bias dan tidak objektif.

Meskipun sentimen anti Syiah tumbuh cukup mengemuka di Manado, namun sentimen itu masih hanya sebatas kekerasan verbal baik di khutbah, ceramah, selebaran, dan juga spanduk. Sejauh ini, belum ada kekerasan fisik yang menimpa penganut Syiah di Manado. Ada beberapa faktor yang menyebabkan hal itu tidak terjadi. Pertama, pemerintah daerah (pemda) cenderung menunjukkan netralitasnya dalam isu agama, sehingga mereka berhati-hati mengeluarkan kebijakan yang dapat menciptakan instabilitas. Hal ini dapat dibaca sebagai bentuk kehati-hatian pemda agar tidak timbul kesan bahwa pemda -yang mana elemenelemen di dalamnya umumnya beragama Kristen- mencampuri urusan internal Islam.

Pemda tentu sangat berkepentingan untuk menjaga toleransi dan harmoni kehidupan umat beragama di Kota Manado karena tema kerukunan di mana slogan torang samua basudara, torang samua ciptaan Tuhan (kita semua bersaudara, kita semua ciptaan Tuhan) dan sito timou tumou tou (manusia hidup untuk menghidupkan orang lain) kerap dijadikan sebagai trademark oleh pemda untuk menggenjot tumbuhnya sektor pariwisata di kota ini. Adanya kehati-hatian dalam mengeluarkan kebijakan paling tidak dapat meredam timbulnya kekerasan. Selama ini, kelompok-kelompok intoleran sering mendasarkan aksi vandalis mereka dengan berlandaskan pada kebijakan pemda, semisal yang 
terjadi pada jamaah Ahmadiyah di Kota Banjar. Jamaah Ahmadiyah yang ada di Kota Banjar mendapatkan kekerasan berupa penyegelan dan pengrusakan masjid Istiqamah JAI setelah munculnya SK Walikota Banjar Nomor 450/Kpts.11-Huk/2011 tentang pembekuan JAI di Kota Banjar (Setara Institute, 2015: 53).

Kedua, sentimen anti Syiah tidak sampai berujung pada kekerasan di Manado karena kelompok Islam intoleran seperti Front Pembela Islam (FPI) dan Aliansi Nasional Anti Syiah (ANNAS) tidak tumbuh subur di Manado. Selama ini menguatnya eskalasi kekerasan yang berbau agama kerap disebabkan oleh adanya propaganda kebencian dan permusuhan yang dilakukan oleh kelompok intoleran. Sejauh ini kelompok masyarakat sipil di Manado cenderung menolak keberadaan kelompok intoleran karena dianggap dapat membawa keresahan dan dapat mengancam kemajemukan yang ada di Kota Manado.

Pasca Aksi Bela Islam 411 dan Aksi Damai 212 di Jakarta tahun 2016 lalu, muncul berbagai penolakan terhadap ormas FPI di Kota Manado oleh berbagai elemen masyarakat sipil. Ketua GP Ansor Kota Manado, Rusli Umar, pasca terjadinya aksi 411 dan 212 di Jakarta menolak dengan keras pengangkatan pimpinan FPI, Habib Rizieq Shihab sebagai imam besar umat Islam Indonesia. Begitu pun dengan komunitas lintas iman di Sulut yang bergabung di bawah payung Gerakan Cinta Damai Sulut (GCDS) menolak kehadiran ANNAS karena dianggap berpotensi mengancam kemajemukan yang ada di Kota Manado. Singkatnya, masyarakat Manado telah terbiasa bersentuhan dengan kemajemukan. Hubungan antara umat Islam dan Kristen selama ini relatif berjalan dengan baik. Apabila dengan umat Kristen saja, umat Islam mampu menjalin hubungan dengan baik dan harmonis, maka tentu tidak akan menjadi sulit bagi umat Islam untuk menjalin hubungan dengan sesama Islam walaupun itu berbeda aliran.

\section{Kesimpulan}

Sentimen Anti Syiah belakangan ini tumbuh menguat di Indonesia. Ia tak hanya terjadi di daerah yang mayoritas Islam, tetapi juga terjadi di daerah minoritas Islam seperti di Manado. Hubungan antara Islam Sunni dan Syiah di Manado cenderung berjalan dinamis. Dulunya hubungan tersebut cenderung berjalan baik, namun hubungan itu mulai memburuk di tahun 2008-2009 dan mencapai puncaknya pada tahun 2012 melalui ujaran kebencian di mimbar-mimbar keagamaan yang dilakukan oleh beberapa mubaligh anti Syiah. Pada tahun 2016, sentimen Anti Syiah menguat kembali Manado setelah munculnya berbagai spanduk "Syiah Bukan Islam" yang kontennya menyerupai spanduk-spanduk kebencian terhadap Syiah yang ada di berbagai kota di Indonesia.

Alasan yang menyebabkan munculnya sentimen anti Syiah di Manado adalah adanya perebutan lahan ekonomi dan juga perebutan kuasa dan pengaruh di antara para mubaligh. Internet dan media sosial juga memainkan peranan penting dalam mengeskalasi kebencian terhadap Syiah karena ia memberikan informasi yang bias dan tidak objektif mengenai Syiah, misalnya Syiah dianggap dalang dari berbagai konflik yang terjadi di Timur Tengah. Untungnya, sentimen anti Syiah di Manado tidak berujung pada kekerasan fisik. Hal ini disebabkan pertama, karena pemda cenderung mengambil kebijakan netral soal agama dan juga tidak ingin mengintervensi lebih jauh tentang urusan internal dalam Islam. Hal ini tidak lepas dari kepentingan pemda untuk menjaga citra kerukunan yang telah melekat pada Kota Manado agar dapat menggenjot tumbuhnya pariwisata. Kedua, kelompok radikal seperti FPI dan ANNAS ditolak kehadirannya di Manado oleh berbagai kelompok masyarakat sipil karena dianggap berpotensi mengancam kemajemukan yang telah terbangun selama ini.

\section{References}

Ali-Fauzi, Ihsan, Rudy Harisyah Alam, Samsu Rizal Panggabean. (2009). Pola-pola Konflik Keagamaan di Indonesia (1990-2008). Jakarta: Yayasan Wakaf Paramadina, MPRKUGM, dan The Asia Foundation.

Amin, Ali. (2013). Revitalisasi Agama di Sulawesi Utara: Kasus Jemaah Aliran Syiah di Manado. 
Laporan Penelitian pada Pusat Penelitian dan Pengabdian Masyarakat IAIN Manado.

Kembuan, Roger A.C. (2016). Jawa Tondano: Sejarah dan Tokoh-Tokoh Yang Diasingkan Abad XIX. Manado: PT. Bank Rakyat Indonesia.

Laporan Kondisi Kebebasan Beragama/Berkeyakinan di Indonesia 2015. (2016). Politik Harapan Minim Pembuktian. (2016). Pustaka Masyarakat Setara.

Laporan Tahunan Kebebasan Beragama dan Berkeyakinan. (2016). Komnas HAM.

Laporan Tahunan Kemerdekaan Beragama dan Berkeyakinan (KBB) di Indonesia. (2015) "Utang" Warisan Tak Kunjung Terlunasi. Jakarta: The Wahid Institute.

Mantu, Rahman. (2015). "Pesantren PKP Kombos: Aktivitas Pesantren di Tengah Mayoritas Masyarakat Kristen", dalam Muhammad Murtadlo, dkk. Pesantren dan Reproduksi Ulama. Jakarta: Pustaka Cendekia Muda.

Wekke, Ismail Suardi. (2013a) "Masjid di Papua Barat: Tinjauan ekspresi keberagamaan minoritas Muslim dalam arsitektur." El-HARAKAH (TERAKREDITASI) 15.2: 124-149.

Wekke, Ismail Suardi. (2013b) "Islam Di Papua Barat: Tradisi Dan Keberagaman." ULUL ALBAB Jurnal Studi Islam 14.2.

Wekke, Ismail Suardi. (2013c) "Lembaga Pendidikan Sebagai Pilar Dakwah di Wilayah Minoritas Muslim." Jurnal Dakwah Alhikmah 4, 2: 93-118.

Wekke, Ismail Suardi. (2017) "Islam dan adat: tinjauan akulturasi budaya dan agama dalam masyarakat Bugis." Analisis: Jurnal Studi Keislaman 13.1 27-56. 